\title{
Doses Reduzidas de Fluazifop-P-BUtil + Fomesafen no Controle de Plantas Daninhas na Cultura de Soj A $^{1}$
}

\author{
Reduced Rates of Fluazifop-p-butil + Fomesafen on Weed Control in Soybean \\ TIMOSSI, P.C. ${ }^{2}$ e DURIGAN, J.C. ${ }^{3}$
}

\begin{abstract}
RESUMO - Com o objetivo de avaliar o efeito de doses reduzidas da mistura formulada de fluazifop-p-butil + fomesafen, aplicado em condições de pós-emergência, no controle de plantas daninhas e na produtividade de dois cultivares de soja, foi instalado um experimento no município de Jaboticabal-SP, ano agrícola de 2000/01. Utilizou-se delineamento experimental em blocos ao acaso, no esquema de parcelas subdivididas, com quatro repetições. Os cultivares IAC - Foscarin 31 e MG/BR46-Conquista constituíram as parcelas, e as doses do herbicida fluazifop-p-butil + fomesafen $(0,4 ; 0,3 ;$ e $0,2 \mathrm{~kg}$ i.a. ha-1), juntamente com as testemunhas (com e sem capinas), as subparcelas. Constatou-se maior fitointoxicação do herbicida no cultivar IAC - Foscarin 31, sem, no entanto, afetar a produção de grãos. Foi possível a redução de até $50 \%$ na dose do herbicida, para o controle da comunidade infestante estudada, com produções estatisticamente iguais ao manejo por capinas durante todo o ciclo.
\end{abstract}

Palavras-chave: Glycine max, herbicidas, manejo integrado.

\begin{abstract}
This experiment was carried out in Jaboticabal, São Paulo - Brazil, during the 2000/01 growing season, to test the effect of reduced doses of formulated mixture of fluazifopp-butil + fomesafen, in postemergence application, on weed control and yield of two soybean cultivars. A randomized block experimental design was used with four replications, in a splitplot design. The cultivars (IAC - Foscarin 31 and MG/BR46-Conquista) constituted the plots and the fluazifop-p-butil + fomesafen herbicide rates $\left(0,4 ; 0,3 ;\right.$ and $0,2 \mathrm{~kg}$. a.i.h $\left.\mathrm{a}^{-1}\right)$, together with the checks (with and without weed), the split-plots. A major phytotoxicity of the herbicide was verified for the IAC - Foscarin 31 cultivar, but without affecting yield. It was possible to reduce the herbicide rates up to 50\% to control this weed community, without significant yield reduction.
\end{abstract}

Key words: Glycine max, herbicide, integrated management.

\section{INTRODUÇÃO}

O controle químico das plantas daninhas constitui-se, atualmente, no método mais utilizado na cultura da soja. No entanto, são necessários mais estudos quanto às doses recomendadas dos herbicidas, pois em algumas situações elas têm sido superestimadas, proporcionando períodos de controle muito superiores aos necessários para determinadas comunidades infestantes. As aplicações em préemergência sem prévio conhecimento do banco de sementes e aquelas em pós-emergência sem a identificação das espécies presentes na comunidade levam a um aumento desnecessário do custo de produção. Além disso, deve-se considerar que a utilização de doses além do necessário pode contaminar o meio ambiente.

Recebido para publicação em 20/2/2002 e na forma revisada em 9/12/2002.

2 Eng.-Agr., Doutorando em Agronomia, área de concentração em Produção Vegetal, pela FCAVJ-UNESP; ${ }^{3}$ Prof. Dr., Titular do Departamento de Fitossanidade da FCAVJ-UNESP, Rod. de acesso Prof. Paulo D. Castellane, s/n, 14884-900 Jaboticabal-SP, <ptimossi@hotmail.com>. 
A integração dos métodos químico e cultural para o controle das plantas daninhas em soja é uma prática recomendada quando se visa a redução nas doses dos herbicidas. Características morfológicas das plantas de soja, relacionadas ao desenvolvimento e sombreamento precoce do solo pelos diferentes cultivares existentes, somadas a densidade adequada e épocas de semeadura, levam à racionalização na utilização de herbicidas (Rassini, 1988).

Blad \& Baker (1972) estudaram a orientação e distribuição das folhas no dossel de diferentes cultivares de soja. O número, o tamanho e a orientação das folhas afetam o índice de área foliar (IAF). Essas diferenças, segundo os autores, influenciam a formação do dossel, que, por sua vez, terá influência no sombreamento imposto pelos cultivares.

Segundo Klingman et al. (1992), uma das premissas básicas para o uso de doses reduzidas de herbicidas é a aplicação sobre plantas daninhas nos estádios iniciais de crescimento, período em que a suscetibilidade é máxima e a possibilidade de recuperação é mínima. Os herbicidas, mesmo em doses reduzidas, controlam plantas daninhas e as mantêm em densidades abaixo do nível de dano, proporcionando produções satisfatórias das culturas (Steckel et al., 1990; Hamill \& Zhang, 1995).

É importante mencionar que esses estudos devem ser regionais, levando-se em consideração as diferenças nos tipos de solo, os principais cultivares e as particularidades dos anos agrícolas (Durigan, 1983), além da época de semeadura (Rassini, 1988). Doses reduzidas de herbicidas satisfazem tanto as necessidades ecológicas quanto as de redução do custo de produção (Carey et al., 1992; Prostko \& Meade, 1993). Entretanto, o agricultor deve assumir o risco do controle inadequado quando os herbicidas são aplicados em doses menores que as recomendadas (Griffin \& Backer, 1990).

O objetivo do presente trabalho foi estudar o efeito de doses reduzidas da mistura formulada fluazifop-p-butil + fomesafen, associadas às características de crescimento e produtividade de dois cultivares de soja em baixa densidade, no controle das plantas daninhas.

Planta Daninha, Viçosa-MG, v.20, n.3, p.439-447, 2002

\section{MATERIAL E MÉTODOS}

O trabalho foi conduzido em área experimental pertencente à Faculdade de Ciências Agrárias e Veterinárias da Universidade Estadual Paulista - UNESP, campus de Jaboticabal, em um Latossolo Vermelho eutrófico típico, de textura argilosa, apresentando topografia suavemente ondulada e condições de boa drenagem.

O solo foi preparado com cinco a dez dias de antecedência da semeadura da soja, com uma aração, seguida de duas gradeações. A semeadura foi realizada em 16.11.2000, colocando-se 27 sementes por metro de sulco com adubação de $250 \mathrm{~kg} \mathrm{ha}^{-1}$ da fórmula NPK 04-20-20 no sulco, baseando-se nos resultados da análise química prévia do solo. Obteve-se densidade média inicial de 11 plantas metro $^{-1}$ para ambos os cultivares, sendo submetidos ao espaçamento de $0,45 \mathrm{~m}$ de entrelinhas. Antes da semeadura realizou-se tratamento de sementes com thiabendazole e thiram, sendo possivelmente o responsável pela baixa porcentagem de emergência de plantas. Foram feitas duas pulverizações com methamidaphos, para controle de percevejos e lagartas desfolhadoras.

O delineamento experimental utilizado foi o de blocos ao acaso, no esquema de parcelas subdivididas, com quatro repetições. Os cultivares IAC - Foscarin 31 e MG/BR46-Conquista, de ciclo precoce e médio, respectivamente (EMBRAPA, 2000), constituíram as parcelas, e as doses do herbicida, juntamente com as testemunhas (com e sem capinas), as subparcelas, perfazendo um total de oito blocos experimentais. Cada unidade experimental constituiu-se de 4,5 m de largura (dez linhas) e 5,0 m de comprimento, perfazendo área total de $22,5 \mathrm{~m}^{2}$.

O herbicida utilizado no experimento foi a mistura pronta de fluazifop-p-butil + fomesafen, na formulação de Solução Aquosa Concentrada (SAqC), contendo $125 \mathrm{~g} \mathrm{~L}^{-1}$ de cada um dos ingredientes ativos. Os tratamentos consistiram da dosagem-padrão recomendada para a cultura da soja - 1,6 L ha-1 p.c. $\left(0,4 \mathrm{~kg}\right.$ i.a. ha $\left.{ }^{-1}\right)$, além de reduções em $25 \%\left(1,2 \mathrm{~L} \mathrm{ha}^{-1}\right.$ p.c. $0,3 \mathrm{~kg}$ i.a. ha- $\left.\mathrm{ha}^{-1}\right)$ e $50 \%\left(0,8 \mathrm{~L} \mathrm{ha}^{-1}\right.$ p.c. $0,2 \mathrm{~kg}$ i.a. ha-1 ${ }^{-1}$. Também foram mantidas duas testemunhas, com e sem capinas, durante todo o ciclo da cultura, para cada cultivar. 
A aplicação do herbicida foi realizada aos 23 dias após a semeadura (DAS), utilizandose pulverizador costal à pressão constante de $35 \mathrm{lb} \mathrm{pol}^{-2}$, com pontas de jato plano tipo XR11002, consumindo o equivalente a $200 \mathrm{~L} \mathrm{ha}^{-1}$ de calda. A umidade relativa do ar era de $70 \%$, com umidade no solo a partir de $0,05 \mathrm{~m}$ de profundidade. As plantas de soja dos cultivares IAC - Foscarin 31 e MG/BR46Conquista estavam no estádio V4 (Fehr \& Caviness, 1977), apresentando 0,11 e 0,16 m de altura, respectivamente.

Determinou-se a densidade das plantas daninhas antes da aplicação do herbicida nas subparcelas em que a cultura permaneceu em convivência durante todo o ciclo. A área total amostrada foi de um metro quadrado por subparcela, arremessando-se, por dez vezes, um retângulo metálico com dimensões de 0,2 x $0,5 \mathrm{~m}$. Além da densidade, identificaram-se as espécies de plantas daninhas que faziam parte da comunidade infestante, bem como suas porcentagens de ocorrência.

As avaliações da densidade das plantas de soja foram feitas no início e final do ciclo, em quatro metros centrais de duas linhas da área útil da subparcela. Aos 10, 20 e 30 dias após a aplicação do herbicida (DAA), procedeu-se à medição da distância descoberta entre os dosséis e a altura das plantas de soja (considerando-se também o dossel formado acima da haste principal), efetuando-se medição com régua graduada. Também foi medida a altura final das plantas aos 115 DAS para o cultivar IAC - Foscarin 31 e aos 133 DAS para o MG/ BR46-Conquista, a qual se deu do colo ao final da haste principal das plantas.

A partir de 15 DAA do herbicida, em intervalos de 14 dias, foram feitas amostragens de plantas de soja para a análise de crescimento, estendendo-se até o estádio R7 (Fehr \& Caviness, 1977) de cada cultivar. O número de avaliações variou com o cultivar.

Em cada amostragem foram coletadas as partes aéreas de três plantas por subparcela nas linhas já designadas para isso e de forma que as plantas sempre fossem retiradas em seqüência na linha, a fim de que as das últimas amostragens não fossem beneficiadas por menor competição intra-específica até esse período. Em cada amostragem também não foram colhidas as plantas que iniciavam a linha novamente, após a lacuna da coleta anterior. Das plantas coletadas, foram retirados 20 folíolos ao acaso, que tiveram a área foliar determinada pelo aparelho "Portable Area Meter" Licor modelo Li-3000A. Por meio da área foliar obtida, determinou-se o índice de área foliar (IAF) total das plantas, segundo metodologia elaborada por Benincasa (1988). Essas mesmas plantas coletadas para análise de crescimento também foram utilizadas na determinação do acúmulo de massa seca total da parte aérea.

As avaliações de controle das plantas daninhas em relação à testemunha sem capinas e dos possiveis sintomas de intoxicação ocasionados pelo herbicida nas plantas de soja foram realizadas, visualmente, aos 5, 15 e 30 dias após a aplicação (DAA). Nas avaliações visuais da eficácia do herbicida para controle das plantas daninhas utilizou-se escala em porcentagem de 0 a 100, em que 0 significava nenhum controle e $100 \%$, controle total. Na avaliação dos sintomas de intoxicação das plantas pelo herbicida adotou-se a escala de notas do EWRC (1964).

Antes de se proceder à colheita da soja nas áreas úteis das subparcelas, foram efetuadas avaliações das porcentagens de acamamento das plantas, considerando-se acamadas as que apresentavam inclinação superior a $45^{\circ} \mathrm{em}$ relação à vertical. Na colheita, que ocorreu aos 115 e aos 133 DAS, para os cultivares IAC Foscarin 31 e MG/BR46-Conquista, respectivamente, as plantas presentes nos quatro metros centrais das duas linhas predeterminadas foram arrancadas manualmente, sendo posteriormente trilhadas. Para a expressão da produtividade e massa de 100 grãos, estes foram corrigidos para 13\% de umidade, com base nas recomendações das Regras para Análise de Sementes (Brasil, 1980).

Com as plantas colhidas na área útil de cada subparcela, além da produtividade, foram determinadas outras características relacionadas à produção, tomando-se dez plantas ao acaso. Essas características foram: altura de inserção da primeira vagem $(\mathrm{cm})$, número de vagens por planta e número de grãos por vagem. Para esta última foi feita a média de 50 vagens por subparcela. 
Os dados obtidos foram submetidos à análise de variância, sendo as médias comparadas pelo teste de Tukey a 5\% de probabilidade (Banzato \& Kronka, 1989).

\section{RESULTADOS E DISCUSSÃO}

A densidade da comunidade infestante na área experimental foi de 92 plantas $\mathrm{m}^{-2}$, composta predominantemente por beldroega (Portulaca oleracea \# POROL), representando $60 \%$ de infestação, variando de 0,01 a $0,10 \mathrm{~m}$ de altura e com até três ramos; capim-colchão (Digitaria horizontalis \# DIGHO), com 20\% da infestação; e capim-carrapicho (Cenchrus echinatus \# CCHEC), com 10\% da infestação, estes últimos com 0,02 a 0,07 m de altura e dois a três perfilhos. Havia outras espécies de plantas daninhas em menor número, como trapoeraba (Commelina benghalensis), anileira (Indigofera hirsuta) e corda-de-viola (Ipomoea spp.). Nesse mesmo município em que foi conduzido o experimento, Durigan (1983), estudando a matocompetição na cultura da soja, relacionou a ocorrência de espécies de plantas daninhas bastante semelhantes, com densidades médias de 70 a 90 plantas $\mathrm{m}^{-2}$.

Aos 23 DAS, o número de plantas de soja por metro de sulco, para ambos os cultivares, foi de 11,0, reduzindo para 9,0 ao final do ciclo, não havendo diferenças estatísticas entre os cultivares e entre os manejos.

Pela Figura 1, constata-se menor controle das plantas daninhas com a redução na dose do herbicida, embora tenham ocorrido acréscimos no controle com o tempo. Essa diferença foi mais evidente aos 5 e 15 DAA, para capimcolchão e capim-carrapicho. Aos 30 DAA, foram observados resultados semelhantes para a porcentagem de controle das plantas daninhas em estudo. Nesta época, a complementação do controle por ambos os cultivares foi de grande importância. Pôde-se observar que na época em que foram semeados, apesar da baixa densidade, houve condições adequadas para a formação de um dossel volumoso, sombreando totalmente as entrelinhas da cultura, mesmo com diferenças marcantes entre os cultivares, o que está de acordo com Rassini (1988). Aos 5 DAA para a beldroega e a partir dos 15 DAA para as demais espécies, verificaram-se porcentagens de controle acima de $80 \%$, demonstrando ser viável a redução na dose do herbicida em até 50\% $\left(0,8 \mathrm{~L} \mathrm{ha}^{-1}\right)$. Mesmo em maior estádio de desenvolvimento em relação às demais espécies em estudo, a beldroega apresentou-se com os melhores resultados. Assim, em áreas com altas densidades de infestações por beldroega, pode-se despender maior intervalo na entrada com aplicações desse herbicida.

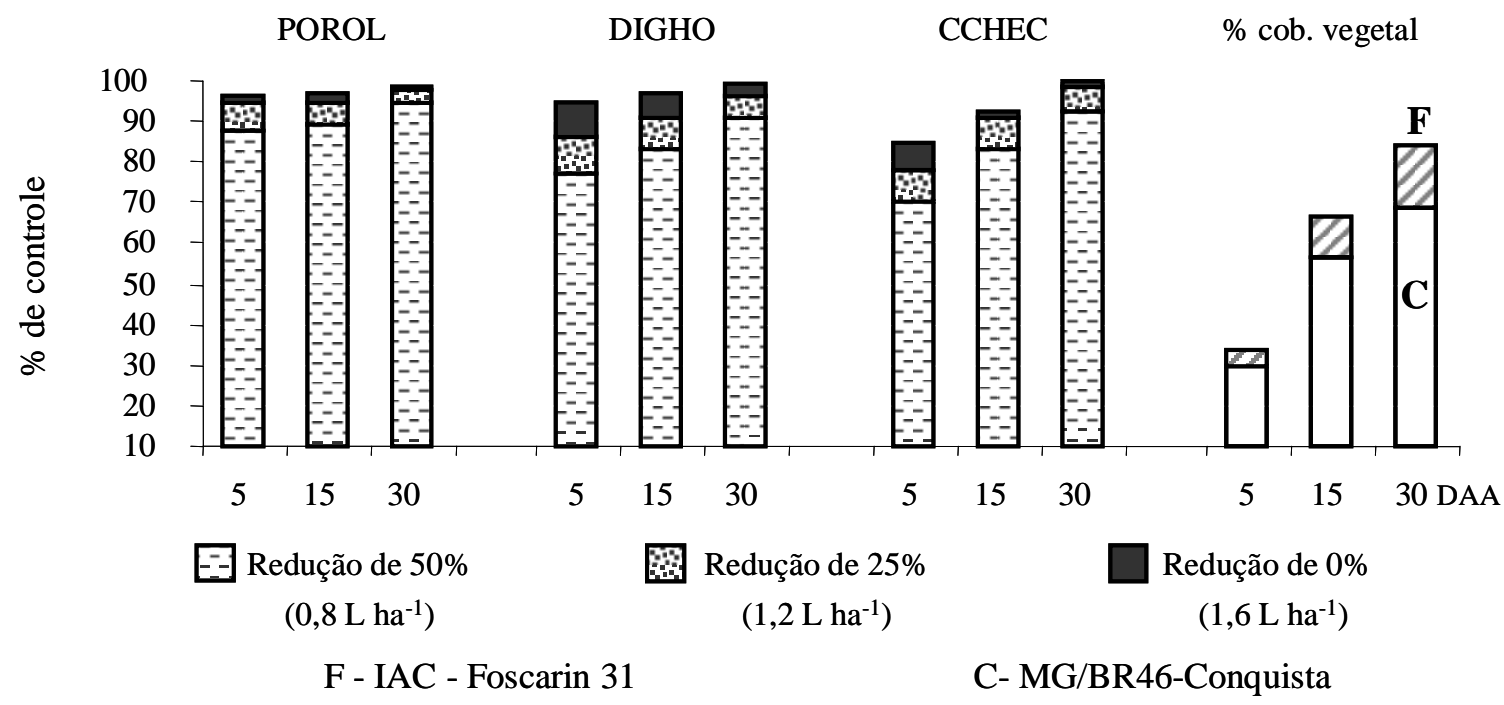

Figura 1 - Médias das porcentagens de controle, atribuídas visualmente, para as principais plantas daninhas da área experimental, aos 5, 15 e 30 DAA da mistura formulada (fluazifop-p-butil + fomesafen) em doses reduzidas, além da cobertura vegetal pela comunidade infestante na testemunha sem capinas dos dois cultivares utilizados. Jaboticabal-SP, 2000/2001. 
Quanto às coberturas vegetais proporcionadas pelas plantas daninhas nas testemunhas sem capinas, notou-se que no decorrer das avaliações sempre houve maior porcentagem de infestação no cultivar IAC - Foscarin 31 , devido às poucas ramificações emitidas, proporcionando menor interceptação de raios solares e menor sombreamento. Na Tabela 1, aos 10 DAA, verificam-se diferenças estatísticas significativas entre cultivares para a distância descoberta entre dosséis, sendo maior para o cultivar IAC - Foscarin 31, permitindo maiores infestações na testemunha sem capinas. Aos 20 DAA já não se constatava diferença estatística. Nesta época, houve diferença significativa dos manejos utilizados em relação à testemunha sem capinas, o que evidencia o efeito da competição no desenvolvimento das plantas e, conseqüentemente, no sombreamento que proporcionam. Aos 30 DAA observou-se fechamento total entre dosséis, para ambos os cultivares.

Quanto à altura de plantas (Tabela 1), os cultivares apresentaram-se no início com desenvolvimento diferenciado. As medições feitas aos 10 DAA evidenciaram isso, pelo fato de apresentarem diferentes hábitos de crescimento (indeterminado para o cultivar IAC -
Foscarin 31 e determinado para o MG/BR46Conquista) e, possivelmente, por terem ocorrido sintomas de fitointoxicação menos intensos no MG/BR46-Conquista com as doses menores do herbicida. Aos 20 e 30 DAA igualaram-se, estatisticamente. Nota-se ainda que a altura de plantas apresentou-se semelhante para os manejos utilizados, em todas as avaliações. $\mathrm{Na}$ avaliação realizada no final do ciclo, constatouse maior altura do cultivar IAC - Foscarin 31 em relação ao MG/BR46-Conquista, evidenciando apenas a característica do hábito de crescimento, pois não se observava mais a ação tóxica do herbicida.

As médias das notas atribuídas visualmente, nas avaliações de fitotoxicidade dos herbicidas em relação às plantas de soja nas diferentes datas após a aplicação do herbicida, são apresentadas na Tabela 2. Aos 5 DAA observou-se maior intoxicação nas plantas do cultivar IAC - Foscarin 31, nas maiores doses do herbicida. Os sintomas de intoxicação ocorreram apenas em folhas existentes no momento da aplicação do herbicida, sendo constatado bronzeamento parcial dos folíolos com necrose marginal, decrescendo os sintomas para as respectivas reduções. Aos 15 DAA, os sintomas tornaram-se menos

Tabela 1 - Valores de F, coeficientes de variação (CV\%) e teste de Tukey aplicados às médias das distâncias descobertas entre os dosséis e à altura $(\mathrm{cm})$ das plantas, em diferentes épocas após a aplicação do herbicida. Jaboticabal-SP, 2000/2001

\begin{tabular}{|c|c|c|c|c|c|c|c|}
\hline & \multirow[t]{2}{*}{ Variável } & \multicolumn{2}{|c|}{$\begin{array}{l}\text { Distância descoberta entre } \\
\text { dosséis }(\mathrm{cm})\end{array}$} & \multicolumn{4}{|c|}{ Altura de plantas $(\mathrm{cm})$} \\
\hline & & $10 \mathrm{DAA}$ & 20 DAA & $10 \mathrm{DAA}$ & $20 \mathrm{DAA}$ & 30 DAA & Final $^{2 /}$ \\
\hline \multirow[t]{3}{*}{$\mathrm{F}$} & Cultivar (C) & $11,09^{*}$ & $4,99^{\text {ns }}$ & $32,53 * *$ & $5,16^{\mathrm{ns}}$ & $0,17^{\mathrm{ns}}$ & 33,32 ** \\
\hline & Manejo (M) & $0,44^{\mathrm{ns}}$ & $12,21^{* *}$ & $0,57^{\mathrm{ns}}$ & $0,23^{\mathrm{ns}}$ & $0,24^{\mathrm{ns}}$ & $3,39 *$ \\
\hline & $\mathrm{C} \times \mathrm{M}$ & $0,63^{\text {ns }}$ & $2,21^{\mathrm{ns}}$ & $1,68^{\mathrm{ns}}$ & $0,63^{\text {ns }}$ & $0,77^{\mathrm{ns}}$ & $2,47^{\mathrm{ns}}$ \\
\hline \multirow[t]{2}{*}{ Cultivar (C) } & IAC - Foscarin 31 & $19,3 \mathrm{a}^{-1 /}$ & 6,6 & $24,5 \mathrm{~b}$ & 53,8 & 82,1 & $107,7 \mathrm{a}$ \\
\hline & MG/BR46-Conquista & $17,2 \mathrm{~b}$ & 7,1 & $29,3 \mathrm{a}$ & 56,1 & 81,2 & $98,1 \mathrm{~b}$ \\
\hline $\mathrm{CV}(\%)$ & & 10,7 & 8,7 & 9,9 & 5,8 & 7,7 & 5,1 \\
\hline DMS & & 2,0 & 0,6 & 2,7 & 3,2 & 6,3 & 5,3 \\
\hline \multirow[t]{5}{*}{ Manejo (M) } & fomesafen + fluaz... $(1,6)^{(3)}$ & 18,6 & $6,7 \mathrm{~b}$ & 27,0 & 54,2 & 81,5 & $104,8 \mathrm{ab}$ \\
\hline & fomesafen + fluaz... $(1,2)$ & 18,2 & $6,3 \mathrm{~b}$ & 27,3 & 55,3 & 81,6 & 106,5 a \\
\hline & fomesafen + fluaz... $(0,8)$ & 18,7 & $5,8 \mathrm{~b}$ & 26,4 & 54,7 & 81,2 & $101,5 \mathrm{ab}$ \\
\hline & Testemunha com capinas & 17,7 & $5,4 \mathrm{~b}$ & 26,7 & 55,3 & 82,5 & $103,1 \mathrm{ab}$ \\
\hline & Testemunha sem capinas & 18,1 & $10,1 \mathrm{a}$ & 26,9 & 55,3 & 81,4 & $98,5 \quad b$ \\
\hline $\mathrm{CV}(\%)$ & & 9,3 & 21,9 & 4,5 & 5,2 & 3,5 & 4,6 \\
\hline DMS & & 2,5 & 2,2 & 1,8 & 4,2 & 4,2 & 6,9 \\
\hline
\end{tabular}

DAA - Dias Após a Aplicação.

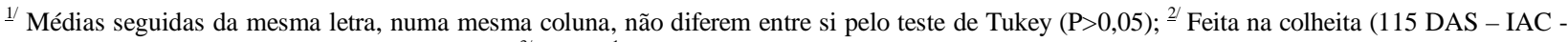
Foscarin 31; 133 DAS - MG/BR46-Conquista); ${ }^{3 /}-\mathrm{L} \mathrm{ha}^{-1}$ do produto comercial. 
perceptiveis, permanecendo apenas nas folhas mais velhas. Folhas novas emitidas após a aplicação do herbicida não apresentavam sintomas. Aos 30 DAA não se constatavam mais sintomas visuais de intoxicação em ambos os cultivares, possivelmente devido à queda das folhas presentes no momento da aplicação.

O conceito de Índice de Área Foliar (IAF) quase ignora a existência do indivíduo e considera a comunidade como um todo. A formação e a manutenção da área foliar de uma cultura são parâmetros estreitamente relacionados com a continuidade do controle proporcionado pelo herbicida no início do ciclo, através do sombreamento nas plantas que germinam após o término do efeito residual do produto (Durigan, 1983).

Embora os cultivares de soja utilizados neste ensaio apresentem características de desenvolvimento diferenciadas, os resultados obtidos evidenciaram maiores diferenças entre eles apenas aos 57 e 71 DAA, pois o cultivar IAC - Foscarin 31, por apresentar ciclo precoce e crescimento indeterminado, encontrava-se nos estádios R6 e R7, respectivamente, com queda contínua de folhas devido à senescência (Figura 2). Aos 85 DAA foi determinado o IAF apenas para o cultivar MG/BR46-Conquista, por apresentar ciclo mais longo. Entre os manejos comparados, a testemunha infestada sempre apresentou os menores índices.

Tabela 2 - Médias das notas atribuídas visualmente para os sintomas de intoxicação às plantas de soja, em três épocas após a aplicação do herbicida. Jaboticabal-SP, 2000/2001

\begin{tabular}{|c|l|c|c|c|c|}
\hline \multirow{2}{*}{ Cultivar } & Manejo & Dose & \multicolumn{3}{|c|}{ Notas $^{\underline{1}}$ de fitointoxicação } \\
\cline { 4 - 7 } & & $\left(\mathrm{L} \mathrm{ha}^{-1}\right)$ & 5 DAA & 15 DAA & 30 DAA \\
\hline \multirow{3}{*}{ IAC-Foscarin 31 } & fomesafen + fluaz... & 1,6 & 5,5 & 2,5 & 1,0 \\
& fomesafen + fluaz... & 1,2 & 4,8 & 2,0 & 1,0 \\
& fomesafen + fluaz... & 0,8 & 3,3 & 1,8 & 1,0 \\
& Test. com capinas & - & 1,0 & 1,0 & 1,0 \\
& Test. sem capinas & - & 1,0 & 1,0 & 1,0 \\
\hline \multirow{3}{*}{ MG/BR46-Conquista } & fomesafen + fluaz... & 1,6 & 4,5 & 2,5 & 1,0 \\
& fomesafen + fluaz... & 1,2 & 3,8 & 1,8 & 1,0 \\
& fomesafen + fluaz... & 0,8 & 3,5 & 2,0 & 1,0 \\
& Test. com capinas & - & 1,0 & 1,0 & 1,0 \\
& Test. sem capinas & - & 1,0 & 1,0 & 1,0 \\
\hline
\end{tabular}

1/ Com base na escala EWRC (1964); DAA - Dias Após a Aplicação.
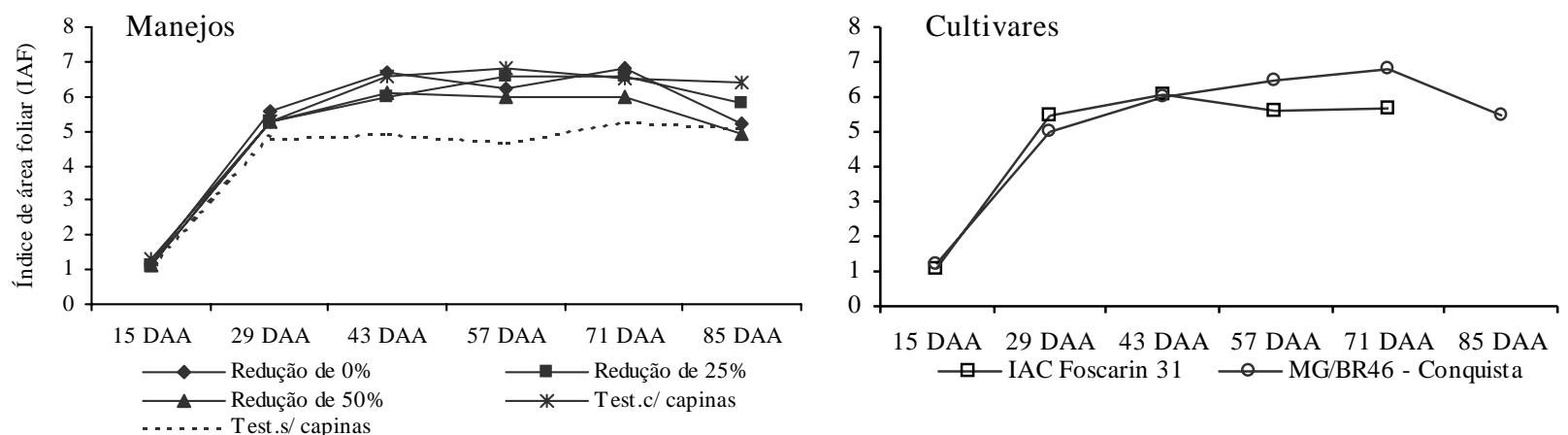

Figura 2 - Índices de área foliar (IAF), para os manejos e cultivares de soja, em avaliações feitas em intervalos de 14 dias até a maturidade fisiológica dos grãos (R7). Jaboticabal-SP, 2000/2001. 
Conforme informações de Pitelli \& Neves (1978), a competição imposta pelas plantas daninhas na cultura da soja afeta negativamente o acúmulo de massa seca nos diversos órgãos da planta, sem contudo alterar a distribuição percentual dela na planta, exceção feita aos estádios finais do ciclo de desenvolvimento. Observando a Figura 3, verifica-se que a massa seca da parte aérea das plantas de soja, sob todos os manejos em que foram efetuadas as reduções do herbicida, apresentouse com resultados semelhantes ao das plantas de soja que foram mantidas sem a presença de plantas daninhas. Os cultivares, mesmo apresentando ciclos biológicos diferenciados, apresentaram igualdade no seu acúmulo de

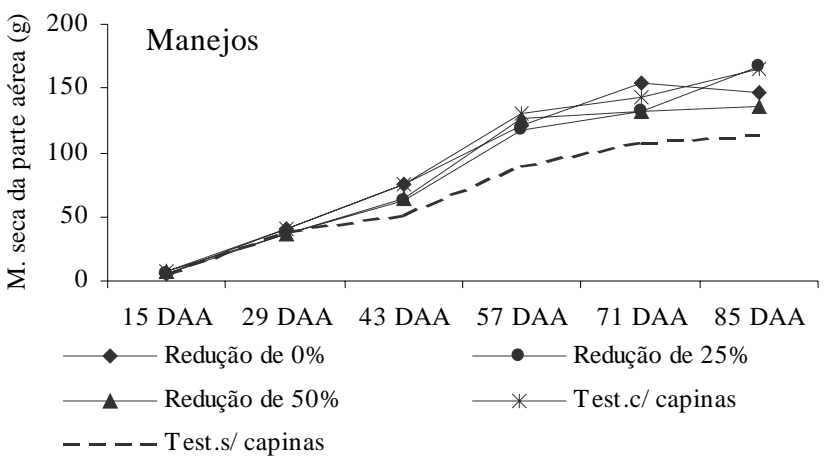

massa seca. Para o cultivar IAC - Foscarin 31, ao mesmo tempo em que ocorria a queda de folhas havia compensação no acúmulo da massa seca das vagens.

Analisando o comportamento dos diferentes manejos com herbicida sobre o desenvolvimento das plantas de soja, refletidos na massa seca, constata-se grande possibilidade de redução na dose da mistura em até $50 \%$ da dose-padrão, para esse tipo de comunidade infestante, sem acarretar prejuízos à produtividade da cultura.

As médias de altura de inserção da primeira vagem, apresentadas na Tabela 3 , mostram diferenças significativas entre cultivares. Para

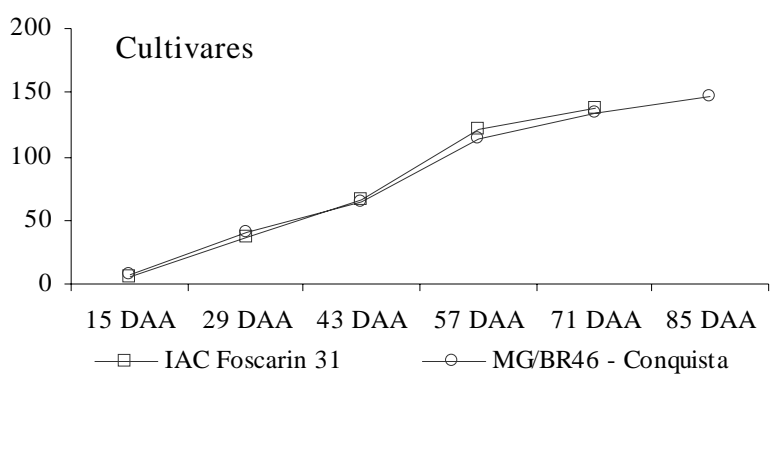

Figura 3 - Evolução do acúmulo de massa seca da parte aérea (g) dos cultivares das plantas de soja e em função dos manejos a que foram submetidos, em avaliações feitas em intervalos de 14 dias até a maturidade fisiológica dos grãos (R7). JaboticabalSP, 2000/2001.

Tabela 3 - Valores de F, coeficientes de variação (CV\%) e teste de Tukey aplicados às médias de porcentagens de acamamento $(\%)$, altura da inserção da primeira vagem $(\mathrm{cm})$, número de vagens por planta, número de grãos por vagem, massa de 100 grãos (g) e produção de grãos $\left(\mathrm{kg} \mathrm{ha}^{-1}\right)$, por ocasião da colheita da soja. Jaboticabal-SP, 2000/2001

\begin{tabular}{|c|c|c|c|c|c|c|c|}
\hline & Variável & $\begin{array}{c}\text { Acamamento } \\
(\%)\end{array}$ & $\begin{array}{c}\text { Altura da } \\
\text { primeira } \\
\text { vagem }(\mathrm{cm})\end{array}$ & $\begin{array}{c}\text { Número de } \\
\text { vagens/planta }\end{array}$ & $\begin{array}{l}\text { Número de } \\
\text { grãos/vagem }\end{array}$ & $\begin{array}{c}\text { Massa de } 100 \\
\text { grãos }(\mathrm{g})\end{array}$ & $\begin{array}{l}\text { Produção de } \\
\text { grãos } \\
\left(\mathrm{kg} \mathrm{ha}^{-1}\right)\end{array}$ \\
\hline $\mathrm{F}$ & $\begin{array}{l}\text { Cultivar (C) } \\
\text { Manejo (M) } \\
\text { C x M }\end{array}$ & $\begin{array}{r}194,01 * * \\
145,28 * * \\
74,97 * *\end{array}$ & $\begin{array}{c}123,09^{* *} \\
2,86^{*} \\
0,34^{\mathrm{ns}}\end{array}$ & $\begin{array}{l}3,53^{\mathrm{ns}} \\
0,28^{\mathrm{ns}} \\
0,95^{\mathrm{ns}}\end{array}$ & $\begin{array}{l}4,04^{\mathrm{ns}} \\
1,06^{\mathrm{ns}} \\
1,95^{\mathrm{ns}}\end{array}$ & $\begin{array}{l}0,00^{\text {ns }} \\
2,58^{\text {ns }} \\
0,42^{\text {ns }}\end{array}$ & $\begin{array}{l}0,22^{\text {ns }} \\
7,70^{* *} \\
2,42^{\text {ns }}\end{array}$ \\
\hline $\begin{array}{l}\text { Cultivar (C) } \\
\text { CV(\%) } \\
\text { DMS }\end{array}$ & $\begin{array}{l}\text { IAC - Foscarin } 31 \\
\text { MG/BR46-Conquista }\end{array}$ & & $\begin{array}{c}15,9 \mathrm{~b}^{1 /} \\
26,7 \mathrm{a} \\
14,5 \\
3,1\end{array}$ & $\begin{array}{r}54,3 \\
51,2 \\
9,9 \\
5,3\end{array}$ & $\begin{array}{l}2,47 \\
2,38 \\
5,4 \\
0,13\end{array}$ & $\begin{array}{c}15,86 \\
15,86 \\
9,7 \\
1,54\end{array}$ & $\begin{array}{r}3027,7 \\
3148,3 \\
26,5 \\
824,5\end{array}$ \\
\hline $\begin{array}{l}\text { Manejo (M) } \\
\text { CV(\%) } \\
\text { DMS }\end{array}$ & $\begin{array}{l}\text { fomesafen + fluaz... }(1,6)^{2 /} \\
\text { fomesafen + fluaz... }(1,2) \\
\text { fomesafen + fluaz... }(0,8) \\
\text { Testemunha com capinas } \\
\text { Testemunha sem capinas }\end{array}$ & & $\begin{array}{r}22,3 \\
19,7 \\
21,9 \\
22,5 \\
20,0 \\
10,5 \\
3,3\end{array}$ & $\begin{array}{l}51,6 \\
53,0 \\
50,7 \\
53,3 \\
53,1 \\
17,8 \\
13,8\end{array}$ & \begin{tabular}{l|}
2,44 \\
2,46 \\
2,38 \\
2,49 \\
2,38 \\
5,4 \\
0,19
\end{tabular} & $\begin{array}{c}16,06 \mathrm{ab} \\
15,76 \mathrm{ab} \\
15,90 \mathrm{ab} \\
16,47 \mathrm{a} \\
15,10 \mathrm{~b} \\
5,6 \\
1,30\end{array}$ & $\begin{array}{c}3075,8 \mathrm{a} \\
3239,8 \mathrm{a} \\
3148,3 \mathrm{a} \\
3438,3 \mathrm{a} \\
2537,8 \mathrm{~b} \\
11,1 \\
505,4\end{array}$ \\
\hline
\end{tabular}

1/ Médias seguidas da mesma letra, numa mesma coluna, não diferem entre si pelo teste de Tukey $(\mathrm{P}>0,05) ;{ }^{2 /} \mathrm{L}$ ha ${ }^{-1}$ do produto comercial. 
a massa de 100 grãos, não foram constatadas diferenças significativas para os manejos; no entanto, pelo teste de Tukey a 5\% de probabilidade, isso ocorreu entre as testemunhas (com e sem capinas). Os manejos químicos apresentaram valores intermediários entre as testemunhas com e sem capinas. A massa dos grãos foi o principal fator a influenciar a produção, pois para as demais características avaliadas não houve diferenças significativas. Para a produção de grãos também houve diferenças significativas entre os manejos; apenas na testemunha sem capina os resultados foram inferiores. Dessa forma, considera-se viável a utilização de doses reduzidas do herbicida visando o controle das plantas daninhas, corroborando as afirmações feitas por Carey et al. (1992), Prostko \& Meade (1993), Steckel et al. (1990) e Hamill \& Zhang (1995).

As porcentagens de acamamento dos cultivares são apresentadas na Tabela 4, com interação significativa entre cultivares e manejos (C x M), havendo maior acamamento para o cultivar IAC - Foscarin 31. Entre os manejos utilizados ocorreram diferenças significativas com a testemunha sem capina. Os maiores percentuais de acamamento nas testemunhas sem capinas foram constatados devido à alta densidade de plantas daninhas em convivência durante todo o ciclo, fazendo com que houvesse a formação de dossel a uma maior altura, além da formação de haste principal menos lignificada. Em virtude da menor

Tabela 4 - Desdobramento da interação significativa das médias estimadas das porcentagens de acamamento, no momento da colheita da soja, para todos os manejos e cultivares estudados. Jaboticabal-SP, 2000/2001

\begin{tabular}{|c|c|c|c|}
\hline \multirow[b]{2}{*}{ Manejo } & \multirow{2}{*}{$\begin{array}{c}\text { Dosagem } \\
\left(\mathrm{L} \mathrm{ha}^{-1}\right)\end{array}$} & \multicolumn{2}{|c|}{ Acamamento (\%) } \\
\hline & & $\begin{array}{c}\text { IAC - } \\
\text { Foscarin } 31\end{array}$ & MG/BR46 \\
\hline fomesafen + fluaz... & 1,6 & $8,2 \mathrm{~b} \mathrm{~A}^{1 / 1}$ & $0,0 \quad \mathrm{~b} \mathrm{~B}$ \\
\hline fomesafen + fluaz... & 1,2 & $11,2 \mathrm{~b} \mathrm{~A}$ & 0,7 b B \\
\hline fomesafen + fluaz... & 0,8 & $15,0 \mathrm{~b} \mathrm{~A}$ & 2,5 b B \\
\hline Testemunha com capinas & - & $7,5 \mathrm{~b} \mathrm{~A}$ & $0,0 \quad \mathrm{~b} \mathrm{~B}$ \\
\hline Testemunha sem capinas & - & $90,0 \mathrm{a} A$ & $13,7 \mathrm{a} \mathrm{B}$ \\
\hline $\operatorname{DMS}(5 \%)$ & & \multirow{2}{*}{\multicolumn{2}{|c|}{10,2}} \\
\hline Manejo d. Cultivar & & & \\
\hline Cultivar d. Manejo & & \multicolumn{2}{|c|}{7,2} \\
\hline
\end{tabular}

1/ Médias na mesma linha, seguidas de letras maiúsculas iguais e na mesma coluna, seguidas de letras minúsculas iguais, não diferem entre si pelo teste de Tukey $(\mathrm{P}>0,05)$. ramificação do cultivar IAC - Foscarin 31, houve maiores espaços nas entrelinhas, facilitando o acamamento dessas plantas.

É possivel concluir que a integração entre os métodos químico e cultural tornou-se viável para a redução em até $50 \%$ na dose do herbicida no controle das plantas daninhas em estudo, para ambas os cultivares, mesmo em baixa densidade. A produtividade foi estatisticamente igual, em face dos níveis de controle proporcionados conjuntamente pela ação do herbicida e complementados pelo sombreamento das plantas de soja. A presença de plantas daninhas durante todo o ciclo da cultura foi responsável por redução em até $26 \%$ na produção de grãos.

\section{AGRADECIMENTOS}

À Fundação de Amparo à Pesquisa do Estado de São Paulo- FAPESP, pela concessão de recursos financeiros e bolsa de estudo, e ao técnico agrícola Gilson José Leite, funcionário da FCAVJ/UNESP, pelo apoio na instalação e condução do experimento.

\section{LITERATURA CITADA}

BANZATO, D. A.; KRONKA, S. N. Experimentação agrícola. Jaboticabal: FUNEP, 1989. 247 p.

BENINCASA, M. M. P. Análise de crescimento de plantas. Jaboticabal: FUNEP, 1988. 42 p.

BLAD, B. N.; BAKER, D. G. Orientation and distribution of leaves within soybean canopies. Agron. J., v. 64, p. 26-29, 1972.

BRASIL. Ministério da Agricultura. Secretaria Nacional de Defesa Agropecuária. Regras para análises de sementes. Brasília: 1980. 188 p.

CAREY, V. F.; SMITH Jr., R. J.; TALBERT, R. E. Reduced and standard herbicide rates for grass control in rice (Oryza sativa). Weed Technol., v. 6, n. 2, p. 409-414, 1992.

DURIGAN, J. C. Matocompetição e comportamento de baixas dosagens de herbicidas, na cultura da soja (Glycine max (L.) Merril). Piracicaba: ESALQ, 1983. 163 p. Tese (Doutorado em Solos e Nutrição de Plantas)Escola Superior de Agricultura Luiz de Queiroz, Universidade de São Paulo, Piracicaba, 1983.

EMPRESA BRASILEIRA DE PESQUISA AGROPECUÁRIA - EMBRAPA. Recomendações técnicas para a cultura da soja na região Central do Brasil, 1999/2000. Londrina, 1999. 226 p. (EMBRAPA soja. Documentos, 132, EMBRAPA Agropecuária Oeste, 5). 
EUROPEAN WEED RESEARCH COUNCIL - EWRC. Report of the $3^{\text {rd }}$, and $4^{\text {th }}$ meetings of EWRC. Comittee of methods in Weed Research. Weed Res., v. 4, p. 88, 1964.

FEHR, W. L.; CAVINESS, C. E. Stages of soybean development. Ames, Yowa. Yowa State University Cooperative Extension Service, 1977, 11p. (Special Report, 80).

GRIFFIN, J. L.; BACKER, J. B. Tolerance of rice (Oryza sativa) cultivars to fenoxaprop, sethoxydim, and haloxyfopmethyl. Weed Sci., v. 38, n. 4, p. 528-531, 1990.

HAMILL, A. S.; ZHANG, J. Quackgrass control with glyphosate and SC-0224 in corn and soybean. Can. J. Plant Sci., v. 75, p. 293-299, 1995.

KLINGMAN, T. E.; KING, C. A.; OLIVER, L. R. Effect of aplication rate, weed species, and stage of growth on imazethapyr activity. Weed Sci., v. 40, n. 2, p. 227-232, 1992.
PITELLI, R. A.; NEVES, A. S. Efeitos da competição das plantas daninhas sobre algumas características morfológicas e agronômicas de plantas de soja. In: SEMINÁRIO BRASILEIRO DE HERBICIDAS E ERVAS DANINHAS, 11; 1978, Fortaleza. Resumos... Fortaleza: 1978. p. 104.

PROSTKO, E. P.; MEADE, J. A. Reduced rates of postemergence herbicides in conventional soybeans (Glycine max). Weed Technol., v. 7, n. 2, p. 365-369, 1993.

RASSINI, J. B. Integração de práticas culturais e baixas dosagens de herbicidas em pós-emergência, para o controle de plantas daninhas na cultura da soja (Glycine $\max ($ L.) Merril). Jaboticabal: UNESP, 1988. 115 p. Tese (Doutorado em Produção Vegetal) - Faculdade de Ciências Agrárias e Veterinárias, Universidade Estadual Paulista, 1988.

STECKEL, L. E.; DEFELICE, M. S.; SIMS, B. D. Integrating reduced rates of postemergence herbicides and cultivation for brodleaf weed control in soybeans (Glycine max). Weed Sci., v. 38, n. 6, p. 541-545, 1990. 